\title{
Effects of sterigmatocystin on TNF- $\alpha$, IL-6 and IL-12 expression in murine peripheral blood mononuclear cells and peritoneal macrophages in vivo
}

\author{
YING ZHANG $^{1}$, ZHI GANG YAO ${ }^{2}$, JUAN WANG ${ }^{1}$, LING XIAO XING ${ }^{2}$, YAN XIA ${ }^{2}$ and XIANG HONG ZHANG ${ }^{1,2}$ \\ ${ }^{1}$ Department of Pathology, the Second Hospital; ${ }^{2}$ The Laboratory of Pathology, \\ Hebei Medical University, Shijiazhuang, Hebei 050017, P.R. China
}

Received October 30, 2011; Accepted January 23, 2012

DOI: $10.3892 / \mathrm{mmr} .2012 .788$

\begin{abstract}
Sterigmatocystin (ST) is a toxic metabolite mainly produced by the fungi Aspergillus nidulans and Aspergillus versicolor. ST is considered a potent carcinogen, mutagen and teratogen. However, over the past few years, it has been demonstrated that it is less acutely toxic to rodents in vivo. In this study, we evaluated the putative effects of ST on the expression of tumor necrosis factor- $\alpha$ (TNF- $\alpha)$, interleukin (IL)-6 and IL-12 at mRNA levels in murine peripheral blood mononuclear cells (mPBMCs) and peritoneal macrophage cells and on the serum TNF- $\alpha$ and IL- 6 levels in BALB/c mice. Our results show the downregulation of TNF- $\alpha$, IL- 6 and IL-12 mRNA expression in mPBMCs and peritoneal macrophage cells using semi-quantitative reverse transcription-polymerase chain reaction following ST treatment by intraperitoneal injection. Additionally, serum TNF- $\alpha$ and IL-6 levels were also decreased as shown by enzyme-linked immunosorbent assay (ELISA). These results suggest that ST contamination has negative immunomodulatory effects through the downregulation of cytokine expression and secretion.
\end{abstract}

\section{Introduction}

Sterigmatocystin (ST), a carcinogenic mycotoxin, is the secondary metabolite of Aspergillus verdicolor and Aspergillus nidulans. ST is one of the most common mycotoxins found in

Correspondence to: Dr Xiang Hong Zhang, Department of Pathology, the Second Hospital, Hebei Medical University, No. 361 Zhongshan East Road, Shijiazhuang, Hebei 050017, P.R. China

E-mail: zhangxianghong2008@163.com

Abbreviations: DMSO, dimethyl sulphoxide; ELISA, enzymelinked immunosorbent assay; GAPDH, glyceraldehyde-3-phosphate dehydrogenase; IFN, interferon; IL, interleukin; mPBMCs, murine peripheral blood mononuclear cells; RT-PCR; reverse transcriptionpolymerase chain reaction; SPF, specific pathogen-free; ST, sterigmatocystin; TNF, tumor necrosis factor

Key words: sterigmatocystin, peripheral blood mononuclear cell, tumor necrosis factor- $\alpha$, interleukin- 6 grains worldwide $(1,2)$. It can even be detected in carpet dust from damp dwellings (3). Until recently, studies on ST have been mainly focused on the mechanisms of toxin production, contamination status and carcinogenic effects (4-6). Few studies have focused on its immunomodulatory effects on cytokine secretion. Previously, we conducted certain preliminary studies on the putative effects of ST on immune cells $(7,8)$. The results showed that ST inhibited the expression and secretion of interleukin (IL)-12 in murine peritoneal macrophages and human peripheral blood mononuclear cells in vitro $(7,8)$, affected IL-2, interferon (IFN)- $\gamma$ and IL-4 expression and secretion of murine spleen cells in vitro (9) and induced the increase of $\mathrm{FoxP}^{+}$regulatory $\mathrm{T}$ cells in lymphatic organs in BALB/c mice in vivo (10). Thus, it is quite clear that the negative immunomodulation is one of the most important biological effects of ST. Further studies on the effects of ST on the immune function are required in order to further elucidate the biohazard of ST contamination.

In the present study, to further evaluate the possible effects of ST on immune cells and cytokines in vivo, we examined the effects of ST on tumor necrosis factor- $\alpha$ (TNF- $\alpha$ ) and IL-6 mRNA expression in murine peripheral blood mononuclear cells (mPBMCs) and on TNF- $\alpha$ and IL-6 serum levels following a single intraperitoneal injection using reverse transcriptionpolymerase chain reaction (RT-PCR) and enzyme-linked immunosorbent assay (ELISA) in BALB/c mice.

\section{Materials and methods}

Animals. Specific pathogen-free (SPF) BALB/c male mice (weighing 16-18 g) were obtained from the Laboratory Animal Center of Hebei Prevince. The mice were kept in isolation cubicles on a ventilated rack at $25^{\circ} \mathrm{C}$ with standard laboratory chow and water ad libitum. Principles of laboratory animal care (http://www.hblac.com/zcfg.htm) were strictly followed during the experiment.

Reagents. ST and dimethyl sulphoxide (DMSO) were purchased from Sigma-Aldrich ( $>98 \%$ purity; St. Louis, MO, USA). The reagents used in RT-PCR, including RNasin, Oligo(dT) $)_{15}$ and TaqDNA polymerase, were purchased from Promega Corporation (Madison, WI, USA). Lymphocyte sepa- 
ration medium was obtained from Tianjin Haoyang Biological Manufacture Co., Ltd. (Tianjin, China). The ELISA kit was purchased from Jingmei Biotech Co., Ltd. (Beijing, China). All other chemicals and reagents were purchased commercially at the highest degree of purity available.

Animal treatment. Ninety-six BALB/c mice were randomly divided into control, solvent control (DMSO) and ST treatment groups, with 32 mice in each group. Mice in the control, DMSO and ST groups were treated with normal saline, DMSO and ST (3 mg/kg) at the same volume by intraperitoneal injection, respectively. ST (1 mg/package) used in this study was first dissolved in $80 \mu \mathrm{l}$ DMSO and then diluted with normal saline to a total volume of $8 \mathrm{ml}$.

At 2, 6, 12 and $24 \mathrm{~h}$ after treatment, mice were sacrificed using eyeball extirpation and blood was collected. Blood samples from 4 mice in each group were collected in autoclaved Eppendorf tubes with anticoagulant for further peripheral blood mononuclear cell separation, while the other 4 samples were used for serum separation.

mPBMC separation. mPBMCs were seperated using the Ficoll-Hypaque density gradient centrifugation method (11). Briefly, each anti-coagulated blood sample $(800 \mu 1)$ was diluted 1:1 with D-Hanks solution, layered onto the lymphocyte separation medium and centrifuged for $15 \mathrm{~min}$ at $500 \mathrm{x} \mathrm{g}$, at $20^{\circ} \mathrm{C}$. The mPBMCs were harvested into Eppendorf tubes (containing 4-5 $\mathrm{ml} \mathrm{D-Hanks)} \mathrm{by} \mathrm{careful} \mathrm{pipetting} \mathrm{of} \mathrm{the}$ corresponding density band and then centrifuged for $15 \mathrm{~min}$ at $500 \mathrm{x}$ g. The sediment was washed in D-Hanks solution $\left(10 \mathrm{~min}\right.$ at $\left.500 \mathrm{x} \mathrm{g}, 4^{\circ} \mathrm{C}\right)$. Finally, the supernatant was discarded and the mononuclear cell layer was collected for RNA extraction.

Murine peritoneal macrophage cell separation. Following the enucleation of the eyeball for blood collection, BALB/c mice were washed in $75 \%$ ethanol. Irrigation of peritoneal cavity was performed with $10 \mathrm{ml}$ ice-cold incomplete RPMI-1640 medium. Emigrated cells in the abdominal cavity were counted and adjusted to $5 \times 10^{6}$ cells $/ \mathrm{ml}$ in RPMI-1640 culture medium containing $10 \%$ fetal calf serum, streptomycin $(100 \mu \mathrm{g} / \mathrm{ml})$ and penicillin (100 units). Macrophage cells were allowed to adhere for $2 \mathrm{~h}$ at $37^{\circ} \mathrm{C}, 5 \% \mathrm{CO}_{2}$. The macrophages were then harvested for RNA extraction.

RNA extraction and cDNA synthesis. Total RNA from mPBMCs was isolated with guanidinium isothiocyanate according to the method of Chomczynski and Sacchi (12). Briefly, extraction solution containing $25 \mathrm{mmol} / 1$ sodium citrate ( $\mathrm{pH} 7.0), 0.5 \%$ sarcosyl and $0.1 \mathrm{~mol} / 1$ 2-mercaptoethanol was combined with the sample at a ratio of $1: 1(\mathrm{v} / \mathrm{v})$ and vortexed for $1 \mathrm{~min}$. For further purification, phenol/chloroform (400 $\mu \mathrm{l}$ phenol/250 $\mu \mathrm{l}$ chloroform) was added and the mixture vortexed for $1 \mathrm{~min}$. After centrifugation at 8,100 x $\mathrm{g}$ for $10 \mathrm{~min}$ at room temperature, the RNA-containing upper aqueous phase was re-extracted with $350 \mu \mathrm{l}$ of chloroform and vortexed for $1 \mathrm{~min}$. After centrifugation again at 8,100 x $\mathrm{g}$ for $10 \mathrm{~min}$ at room temperature, RNA was precipitated with $1 \mathrm{ml}$ of isopropanol supplemented with $40 \mu \mathrm{l}$ of $2 \mathrm{M}$ sodium acetate ( $\mathrm{pH} 4.0)$ at $-80^{\circ} \mathrm{C}$ for $1 \mathrm{~h}$. The RNA was pelleted by centrifugation at
$16,000 \mathrm{x}$ g for $20 \mathrm{~min}$ at $4^{\circ} \mathrm{C}$, washed with $1 \mathrm{ml}$ of cold $70 \%$ ethanol and centrifuged again at $16,000 \mathrm{x}$ g for $15 \mathrm{~min}$ at $4^{\circ} \mathrm{C}$. Precipitated RNA was air-dried, resuspended in DEPC-treated water and stored at $-80^{\circ} \mathrm{C}$.

The primers were set as described in Table I. The primers for glyceraldehyde-3-phosphate dehydrogenase (GAPDH) cDNA gene were used as the internal control for relative mRNA quantification and the results were calculated after standardization on GAPDH mRNA content.

The reactions were incubated in a PCR thermal cycle (GeneAmp PCR system 9600; PerkinElmer, USA) at $94^{\circ} \mathrm{C}$ for $5 \mathrm{~min}$ and followed by 30 cycles at $94^{\circ} \mathrm{C} / 50 \mathrm{sec}, 54^{\circ} \mathrm{C} / 30 \mathrm{sec}$ and $72^{\circ} \mathrm{C} / 30 \mathrm{sec}$, with a final 10 -min extension at $72^{\circ} \mathrm{C}$. Following amplification, each sample was analyzed by $1.5 \%$ agarose gel electrophoresis and visualized by ethidium bromide staining.

ELISA. The TNF- $\alpha$ and IL-6 levels in the serum were determined using the mice TNF- $\alpha$ and IL- 6 instant ELISA kit. The IL- 6 and TNF- $\alpha$ determination was performed according to the manufacturer's instructions.

Statistical analysis. All results were expressed as the means \pm SD for each group. Statistical analysis was performed with one-way analysis of variance (ANOVA) and bivariate correlation. All statistical analyses were calculated using SPSS 13.0 statistical software. P-values $<0.05$ were considered to be indicate statistically significant differences.

\section{Results}

TNF- $\alpha, I L-6$ and IL-12 mRNA in mPBMCs. RT-PCR analysis revealed no significant difference in TNF- $\alpha$ expression between the control and the DMSO groups. However, the expression of TNF- $\alpha$ in the ST treatment group was significantly decreased compared to that in the control and DMSO groups, as shown in Fig. 1A. The lowest TNF- $\alpha$ mRNA expression was observed following ST treatment for $6 \mathrm{~h}$.

Fig. 1B depicts that IL- 6 mRNA expression in the ST treatment group varied with treatment time. The expression of IL-6 mRNA in mPBMCs at 2 and $6 \mathrm{~h}$ after ST treatment showed an obvious increase compared to that in the corresponding control and solvent control groups. As the ST treatment time was prolonged, the IL- 6 mRNA expression levels began to decrease, with the lowest levels found in the 24-h treatment group.

As shown in Fig. 1C, there was no significant difference in IL-12p35 expression between the control and solvent control groups. The relative expression levels of IL-12p35 mRNA in the 2-, 6-, 12- and 24-h ST treatment groups were 0.33 \pm 0.06 , $0.29 \pm 0.07,0.30 \pm 0.04$ and $0.35 \pm 0.05$, respectively. All were significantly lower compared to those in the corresponding DMSO groups $(0.66 \pm 0.10,0.69 \pm 0.13,0.71 \pm 0.05$ and $0.73 \pm 0.16$, respectively; $\mathrm{p}<0.01)$.

TNF- $\alpha, I L-6$ and IL-12 mRNA in peritoneal macrophages. RT-PCR analysis showed that there was no significant difference in the expression of TNF- $\alpha$ mRNA between the control and solvent control groups. The relative expression levels of TNF- $\alpha$ mRNA in the 2-, 6-, 12- and 24-h ST treatment groups were significantly lower than those in the solvent group at the same time-points $(\mathrm{p}<0.05$; Fig. $2 \mathrm{~A})$. A negative correlation 
Table I. Primers used in this study.

\begin{tabular}{llc}
\hline Primer & \multicolumn{1}{c}{ Sequence } & Length (bp) \\
\hline TNF- $\alpha$ sense & 5'-AGCCGATGGGTTGTA-3' \\
TNF- $\alpha$ antisense & 5'-ACTTGGGCAGATTGA-3' \\
IL-6 sense & 5'-GCCTTCTTGGGACTGATG-3' \\
IL-6 antisense & 5'-CTGGCTTTGTCTTTCTTGTTA-3' \\
IL-12p35 sense & 5'-GGACCAAACCAGCACAT-3' \\
IL-12p35 antisense & 5'-CGCAGAGTCTCGCCATTA-3' \\
IL-12p40 sense & 5'-TGTTGTAGAGGTGGACTGG-3' \\
IL-12p40 antisense & 5'-CGCAGAGTCTCGCCATTA-3' \\
GAPDH sense & 5'-CGGTGCTGAGTATGTCGT-3' \\
GAPDH antisense & 5'-AGGTGGAAGAGTGGGAGT-3'
\end{tabular}

TNF, tumor necrosis factor; IL, interleukin; GAPDH, glyceraldehyde-3-phosphate dehydrogenase.
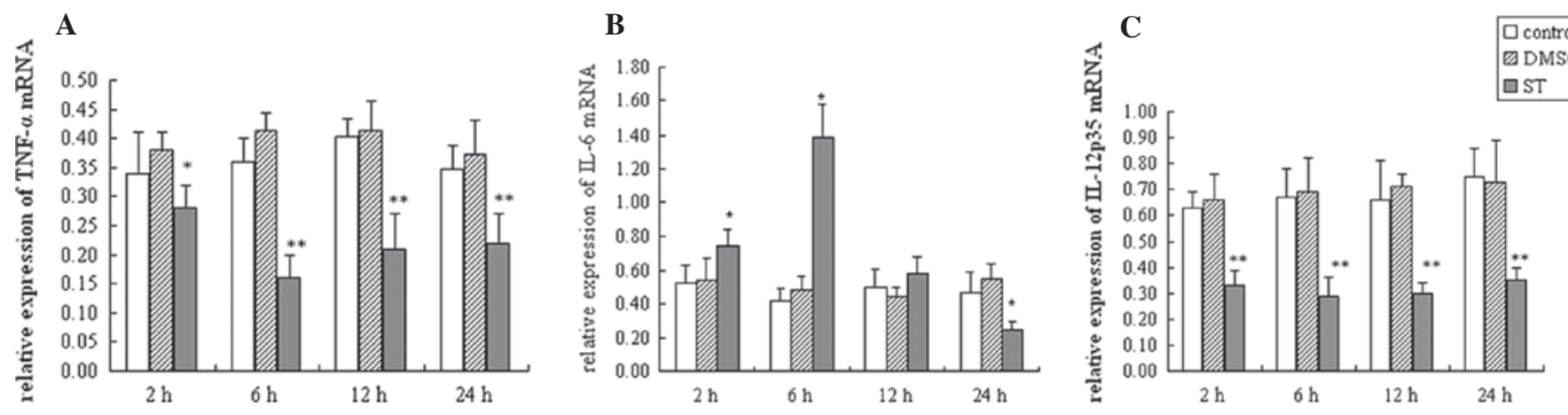

Figure 1. Effects of ST on TNF- $\alpha$, IL-6 and IL-12 mRNA expression in mPBMCs of BALB/c mice. (A) The expression of TNF- $\alpha$ in the ST treatment groups was significantly decreased compared to that in the control and DMSO groups. (B) IL-6 mRNA expression in mPBMCs at 2 and $6 \mathrm{~h}$ after ST treatment showed an obvious increase compared to that in the corresponding control and solvent control groups. (C) IL-12p35 mRNA levels were significantly lower than those in the corresponding DMSO groups at $24 \mathrm{~h}$. Means $\pm \mathrm{SD}, \mathrm{n}=4 ;{ }^{* * *} \mathrm{p}<0.01$ compared to the corresponding DMSO group. TNF, tumor necrosis factor; IL, interleukin; mPBMCs, murine peripheral blood mononuclear cells; DMSO, dimethyl sulphoxide.
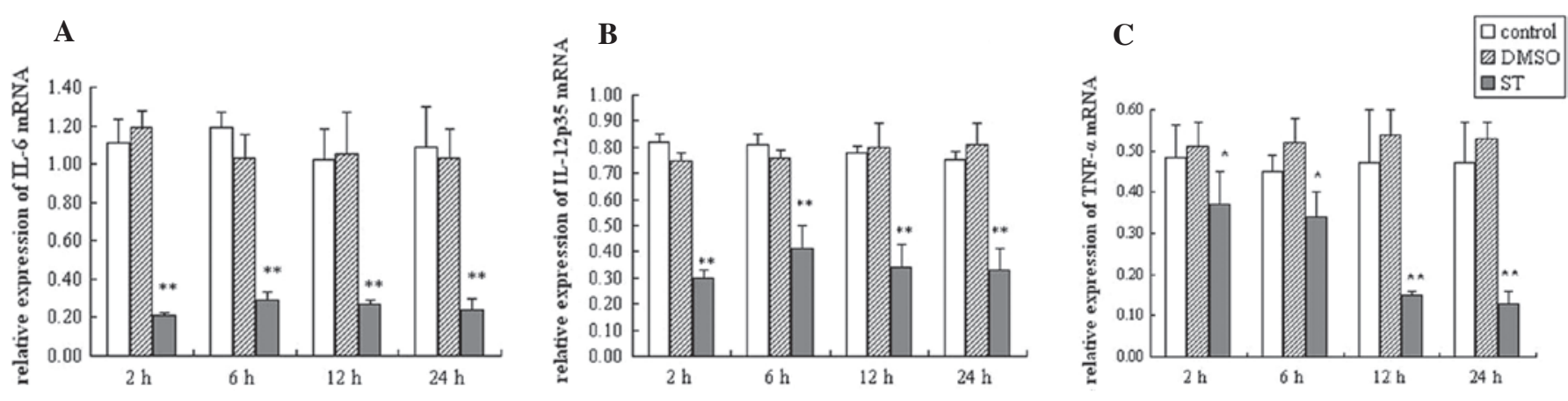

Figure 2. Effects of ST on TNF- $\alpha$, IL-6 and IL-12 mRNA expression in murine peritoneal macrophages in BALB/c mice. (A) IL-6 mRNA expression in mPBMCs was significantly lower compared to that in the corresponding control and solvent control groups. (B) IL-12p35 mRNA levels were also decreased following ST treatment at $24 \mathrm{~h}$. (C) The expression of TNF- $\alpha$ in the ST treatment groups was significantly downregulated. Means \pm SD, n=4; ${ }^{* * *}$ p $<0.01$ compared to the corresponding DMSO group. TNF, tumor necrosis factor; IL, interleukin; mPBMCs, murine peripheral blood mononuclear cells; DMSO, dimethyl sulphoxide.

between ST treatment time and TNF- $\alpha$ mRNA expression was found $(\mathrm{r}=-0.833, \mathrm{p}<0.01)$.

The expression of IL- 6 mRNA in the ST treatment groups at 2, 6, 12 and $24 \mathrm{~h}$ was significantly lower than in the DMSO group ( $<<0.01$; Fig. 2B). However, no significant difference was found among the ST treatment groups at the time-points evaluated. The expression of IL-12p35 mRNA was inhibited after ST treatment for 2, 6, 12 and $24 \mathrm{~h}$ (p<0.01; Fig. 2C).

TNF- $\alpha$ and IL- 6 serum levels in BALB/c mice. The ELISA results revealed that the serum TNF- $\alpha$ and IL- 6 levels after ST treatment for 2, 6, 12 and $24 \mathrm{~h}$ were all significantly lower compared to those 
Table II. TNF- $\alpha$ in serum of mice (Means $\pm \mathrm{SD}, \mathrm{n}=4)(\mathrm{pg} / \mathrm{ml})$.

\begin{tabular}{lccrr}
\hline Group & $2 \mathrm{~h}$ & $6 \mathrm{~h}$ & $12 \mathrm{~h}$ & $24 \mathrm{~h}$ \\
\hline Control & $12.03 \pm 0.90$ & $11.61 \pm 1.53$ & $11.05 \pm 1.00$ & $11.53 \pm 1.22$ \\
DMSO & $11.43 \pm 0.60$ & $12.17 \pm 1.04$ & $11.69 \pm 1.53$ & $12.43 \pm 1.40$ \\
ST & $9.14 \pm 0.58^{\mathrm{a}}$ & $8.57 \pm 0.57^{\mathrm{a}}$ & $0.00 \pm 0.00^{\mathrm{a}}$ & $0.00 \pm 0.00^{\mathrm{a}}$ \\
\hline
\end{tabular}

One-way ANOVA. ${ }^{\mathrm{a}} \mathrm{p}<0.05$ compared to the corresponding DMSO group. $\mathrm{r}=-0.905, \mathrm{p}<0.05$. TNF, tumor necrosis factor; DMSO, dimethyl sulphoxide; ST, sterigmatocystin.

Table III. IL-6 in serum of mice (Means $\pm \mathrm{SD}, \mathrm{n}=4)(\mathrm{pg} / \mathrm{ml})$.

\begin{tabular}{lcrrr}
\hline Group & $2 \mathrm{~h}$ & $6 \mathrm{~h}$ & $12 \mathrm{~h}$ & $24 \mathrm{~h}$ \\
\hline Control & $11.40 \pm 3.70$ & $12.03 \pm 1.20$ & $10.67 \pm 1.58$ & $11.63 \pm 1.52$ \\
DMSO & $10.63 \pm 1.58$ & $11.63 \pm 1.52$ & $12.25 \pm 1.26$ & $10.90 \pm 1.14$ \\
ST & $7.32 \pm 1.10^{\mathrm{a}}$ & $7.00 \pm 1.00^{\mathrm{a}}$ & $0.00 \pm 0.00^{\mathrm{a}}$ & $0.00 \pm 0.00^{\mathrm{a}}$ \\
\hline
\end{tabular}

One-way ANOVA. ${ }^{\mathrm{p}} \mathrm{p}<0.05$ compared to the corresponding DMSO group. $\mathrm{r}=-0.933, \mathrm{p}<0.05$. IL, interleukin, DMSO, dimethyl sulphoxide; ST, sterigmatocystin.

in the corresponding control and solvent control groups (TNF- $\alpha$, $\mathrm{p}<0.05$; IL-6, $\mathrm{p}<0.05$; Tables II and III). TNF- $\alpha$ and IL-6 were not detected in the serum after ST treatment for 12 and $24 \mathrm{~h}$. The serum TNF- $\alpha$ and IL-6 levels were negatively correlated with ST treatment time $(\mathrm{TNF}-\alpha, \mathrm{r}=-0.905, \mathrm{p}<0.05 ; \mathrm{IL}-6, \mathrm{r}=-0.933, \mathrm{p}<0.05)$.

\section{Discussion}

Health risks from mycotoxins encountered in food and grains as well as in the environment continue to be a worldwide concern. Mycotoxins are a group of structurally diverse fungal secondary metabolites that elicit a wide spectrum of toxicological effects (13). It has been reported that certain mycotoxins alter normal immune function when present in food at levels below observable overt toxicity (14). As we know, cytokines are involved in many crucial processes in the regulation of immune responses, such as antigen presentation, antigen recognition, differentiation and maturity of lymphocyte and antibody production. TNF- $\alpha$, IL- 6 and IL-12 are important pro-inflammatory cytokines secreted by peripheral blood mononuclear cells, including lymphocytes and monocytes. TNF- $\alpha$ plays an important role in the development of cellmediated immunity through IL-12 and IL-6 generations (15). IL-12 (p75) contains two different disulfide-linked subunits that have molecular weights of $35 \mathrm{kDa}(\mathrm{p} 35)$ and $40 \mathrm{kDa}(\mathrm{p} 40)$. The principal biological effect of IL-12p75 is to upregulate the Th1 response via the induction of IFN- $\gamma$ production, T-cell proliferation and enhancement of natural killer cell-mediated cytotoxicity (16). IL-6 leads to the activation of T cells, differentiation of end-stage B cells and immunoglobulin secretion, and thus is an important factor in chronic inflammation, acute phase responses and growth stimulation (17).

In this study, the results showed that ST significantly downregulated the expression of TNF- $\alpha$ and IL- 6 at mRNA levels following ST treatment. At the same time, serum TNF- $\alpha$ and IL-6 levels were also decreased following ST treatment. In addition, ST also decreased the expression of IL-12p35 mRNA both in mPBMCs and peritoneal cells. These results confirm that ST has negative immunomodulatory effects, which may be correlated with the expression and secretion of many important pro-inflammatory cytokines (TNF- $\alpha$, IL-6 and IL-12) in mPBMCs and peritoneal macrophages, leading to the depression of lymphocyte activity and systemic host defense systems.

There has been growing concern regarding the effects of mycotoxins on the expression and secretion of certain cytokines (18-21). TNF- $\alpha$ and IL-12 production is reduced in mouse peritoneal macrophages and lymph node $\mathrm{T}$ cells by $\mathrm{T}-2$ toxin, which is a mycotoxin of type A trichothecenes produced by several fungal genera, such as the Fusarium species (22). TNF- $\alpha$ mRNA levels have also been shown to be decreased in swine alveolar macrophages after Fumonisin B1 incubation (23). IL-6 production in human lymphocytes was inhibited by deoxynivalenol (DON), a type B trichothecene (24). Citrinin from Penicillium citrinum or gliotoxin from Gliocladium virens have been shown to significantly reduce IL-6 levels in the A549 human alveolar epithelial carcinoma cell line (24). Thus, this suggests that the downregulation of cytokine production plays a significant role in the negative immunomodulatory effects of several mycotoxins. The results from our study confirm that, similar to T-2, Fumonisin B1 and DON, the carcinogenic mycotoxin, sterigmatocystin, significantly downregulates the expression of TNF- $\alpha$, IL-6 and IL-12p35 in mPBMCs, and thus has negative immunomodulatory effects. Despite its preliminary character, this study further elucidates the negative effects of ST on immune cells and cytokines.

\section{Acknowledgements}

The authors would like to thank all the participants and collaborators in this study. This study was supported by the 
Key (Key grant) Project of the Chinese Ministry of Education (No. 205021).

\section{References}

1. Sivakumar V, Thanislass J and Niranjali S: Lipid peroxidation as a possible secondary mechanism of sterigmatocystin toxicity. Hum Exp Toxicol 20: 398-403, 2001.

2. Tian H and Liu X: Survey and analysis on sterigmatocystin contaminated in grains in China. Wei Sheng Yan Jiu 33: 606-608, 2004.

3. Engelhart S, Loock A, Skutlarek D, et al: Occurrence of toxigenic Aspergillus versicolor isolates and sterigmatocystin in carpet dust from damp indoor environments. Appl Environ Microbiol 68: 3886-3890, 2002.

4. Bloom E, Nyman E, Must A, Pehrson C and Larsson L: Molds and mycotoxins in indoor environments - a survey in waterdamaged buildings. J Occup Environ Hyg 6: 671-678, 2009.

5. Cary JW, Ehrlich KC, Beltz SB, Harris-Coward P and Klich MA Characterization of the Aspergillus ochraceoroseus aflatoxin/ sterigmatocystin biosynthetic gene cluster. Mycologia 101: 352-362, 2009.

6. Zhang XH and Xue LY: Carcinogenicity and biological effectiveness of sterigmatocystin. Zhonghua Bing Li Xue Za Zhi 38 $136-138,2009$.

7. Xing LX, Zhang XH, Yin GR, Li YH, Wang JL, Yan X and Wang FR: Effect of sterigmatocystin on interleukin-12 expression and secretion of murine peritoneal macrophage cells in vitro Zhongguo Yao Li Xue Yu Du Li Xue Za Zhi 19: 205-208, 2005.

8. Huang XH, Zhang XH, Yan X and Yin GR: Effects of sterigmatocystin on interleukin-2 secretion of human peripheral blood mononuclear cells in vitro. Wei Sheng Yan Jiu 31: 112-114, 2002.

9. Xing LX, Zhang XH, Li YH, Yan X, Wang JL and Wang FR: Effects of sterigmatocystin on IL-2 and IFN- $\gamma$ secretion and expression in murine spleen cells in vitro. Zhongguo Bing $\mathrm{Li}$ Sheng Li Za Zhi 20: 306-310, 2004.

10. Liu YL, Xing X, Xing LX, Yao ZG, Wang J, Yan X, et al: Effect of sterigmatocystin on transcription factor Foxp $3^{+}$regulatory $\mathrm{T}$ lymphocytes of thymus and spleen in mice. Zhong Guo Yao Li Xue Yu Du Li Xue Za Zhi 23: 188-194, 2009.

11. Bicalho HM, Gontijo CM and Nogueira-Machado JA: A simple technique for simultaneous human leukocytes separation. J Immunol Methods 40: 115-116, 1981.
12. Chomczynski P and Sacchi N: Single-step method of RNA isolation by acid guanidinium thiocyanate-phenol-chloroform extraction. Anal Biochem 162: 156-159, 1987.

13. Oswald IP, Marin DE and Bouhet S: Immunotoxicological risk of mycotoxins for domestic animals. Food Addit Contam 22: 354-360, 2005.

14. Mbandi E and Pestka JJ: Deoxynivalenol and satratoxin G potentiate proinflammatory cytokine and macrophage inhibitory protein 2 induction by Listeria and Salmonella in the macrophage. J Food Prot 69: 1334-1339, 2006.

15. Fiers W: Tumor necrosis factor: characterization at the molecular, cellular and in vivo level. FEBS Lett 285: 199-212, 1991.

16. Nickbarg EB, Vath JE, Pittman DD, Leonard JE, Waldburger KE and Bond MD: Structural characterization of the recombinant P40 heavy chain subunit monomer and homodimer of murine IL-12. Bioorg Chem 23: 380-396, 1995.

17. Gabay C: Interleukin-6 and chronic inflammation. Arthritis Res Ther 8: S3, 2006

18. Bruneau J, Loscher C and O'Kennedy R: Investigation of the immuno-modulatory effects of aflatoxin B1, B2 and G1. Epidemiology 20: S42-S43, 2009.

19. Severino L, Luongo D, Bergamo P, Lucisano A and Rossi M: Mycotoxins nivalenol and deoxynivalenol differentially modulate cytokine mRNA expression in Jurkat T cells. Cytokine 36: 75-82, 2006.

20. Taranu I, Marin DE, Bouhet S, Pascale F, Bailly JD, Miller JD, Pinton P and Oswald IP: Mycotoxin fumonisin B1 alters the cytokine profile and decreases the vaccinal antibody titer in pigs. Toxicol Sci 84: 301-307, 2005.

21. Marin ML, Murtha J, Dong W and Pestka JJ: Effects of mycotoxins on cytokine production and proliferation in EL-4 thymoma cells. J Toxicol Environ Health 48: 379-396, 1996.

22. Thuvander A, Wikman C and Gadhasson I: In vitro exposure of human lymphocytes to trichothecenes: individual variation in sensitivity and effects of combined exposure on lymphocyte function. Food Chem Toxicol 37: 639-648, 1993.

23. Liu BH, Yu FY, Chan MH and Yang YL: The effects of mycotoxins, fumonisin B1 and aflatoxin B1, on primary swine alveolar macrophages. Toxicol Appl Pharmacol 180: 197-204, 2002.

24. Johannessen LN, Nilsen AM and Løvik M: Mycotoxin-induced depletion of intracellular glutathione and altered cytokine production in the human alveolar epithelial cell line A549. Toxicol Lett 168: 103-112, 2007. 